\title{
Rationing Access to Protected Natural Areas: An Australian Case Study
}

\author{
CHRISTOPHER M. FLEMING ${ }^{1}$
}

\section{MATTHEW MANNING ${ }^{2}$}

Social and Economic Research Program (SERP)

Griffith University

QLD, Australia.

In Australia, as in many other parts of the world, open access is the default policy setting for most protected natural areas, including World Heritage sites. This is despite considerable evidence that unrestrained levels of visitation can be unsustainable in terms of impact on the environment and recreational experience. This paper seeks to answer two questions: First, to what extent are visitors willing to forego access to publicly owned protected natural areas in order to ensure less crowding and/or better environmental outcomes? And second, if access were restricted, how would visitors like remaining access rights to be allocated? Results show that visitors are, in general, willing to trade off some degree of access rights for better environmental outcomes and reduced crowding; particularly the former. It is clear that peak pricing is not supported, whereas visitor caps have broad support.

Key words Lake McKenzie, Fraser Island, choice modelling, visitor management, protected areas, visitor attitudes.

Running head Rationing Access to Protected Natural Areas

\footnotetext{
${ }^{1}$ Social and Economic Research Program (SERP), Griffith University, Nathan, QLD 4111, Australia. Corresponding Author: Email chris.fleming@griffith.edu.au; Ph. +61 7373 7061; Fax +61 737357760.

${ }^{2}$ Centre for Aboriginal Economic Policy Research, Australian National University, ACT 0200, Australia; Social and Economic Research Program (SERP).
} 


\section{Acknowledgements}

This research was funded by a Queensland Department of Premier and Cabinet 'Smart State' Grant. The authors would like to thank an anonymous reviewer, Clem Tisdell, Averil Cook and Christopher Ambrey for useful feedback. Thanks also to the staff at the Queensland Parks and Wildlife Service for

providing data and advice. Views expressed in this paper do not necessarily reflect those of Queensland Parks and Wildlife Service staff. All errors and omissions remain the authors. 


\section{Rationing Access to Protected Natural Areas: An Australian Case Study}

In Australia, as in many other parts of the world, open access is the default policy setting for most protected natural areas, including World Heritage sites. This is despite considerable evidence that unrestrained levels of visitation can be unsustainable in terms of impact on the environment and recreational experience. This paper seeks to answer two questions: First, to what extent are visitors willing to forego access to publicly owned protected natural areas in order to ensure less crowding and/or better environmental outcomes? And second, if access were restricted, how would visitors like remaining access rights to be allocated? Results show that visitors are, in general, willing to trade off some degree of access rights for better environmental outcomes and reduced crowding; particularly the former. It is clear that peak pricing is not supported, whereas visitor caps have broad support.

Key words Lake McKenzie, Fraser Island, choice modelling, visitor management, protected areas, visitor attitudes.

Running head Rationing Access to Protected Natural Areas 
The National Parks present another instance of the working out of the tragedy of the commons. At present, they are open to all, without limit. The parks themselves are limited in extent - there is only one Yosemite Valley - whereas population seems to grow without limit. The values that visitors seek in the parks are steadily eroded. Plainly, we must soon cease to treat the parks as commons or they will be of no value to anyone.

What shall we do? We have several options. We might sell them off as private property. We might keep them as public property, but allocate the rights to enter them. The allocation might be on the basis of wealth, by the use of an auction system. It might be on the basis of merit, as defined by some agreed-upon standards. It might be by lottery. Or it might be on a first-come, first-served basis, administered to long queues. These, I think, are all the reasonable possibilities. They are all objectionable. But we must choose - or acquiesce in the destruction of the commons we call our National Parks.

(Hardin, 1968 p.1245)

\section{Introduction}

As illustrated by the above quotation, the issues that this paper seeks to address are not new. Nonetheless, more than forty years after Hardin's seminal article was published, the problem of unrestrained recreational use of protected natural areas remains largely unresolved. In Australia (as in many other parts of the world) open access is the default policy setting for most protected natural areas, including World Heritage sites. This is despite considerable evidence that, in many cases, current levels of visitation are unsustainable in terms of impact on the environment and recreational experience. Unfortunately, there seems to be little concerted research undertaken to explore visitors' preferences for alternative management regimes to justify the current stance; it is simply assumed that 
visitors would oppose any attempt to ration access. ${ }^{3}$ The primary purpose of this paper is to test this assumption.

More specifically, using Lake McKenzie (situated on Queensland's World Heritage listed Fraser Island) as a case study site and employing the choice modelling non-market valuation technique, this paper seeks to answer two questions: First, to what extent are visitors willing to forego access to publicly owned protected natural areas in order to ensure less crowding and/or better environmental outcomes? And second, if access were restricted, how would visitors like remaining access rights to be allocated? The objective of the paper is, therefore, to test the 'open access at all costs' approach to managing protected natural areas, as well as to offer guidance to policy makers regarding the preferences of visitors for alternative management options.

These questions are timely in that the centre-right Queensland State Government campaigned on an election platform of increasing access to national parks and has announced a review of the Nature Conservation Act 1992, identifying “...a range of reforms to the Act which would increase access to national parks and other public lands for the enjoyment of all Queenslanders” (Queensland Government, 2012b). Proposed policy measures include reopening beaches to 4WD vehicles, extending recreational facilities within national parks and reducing the regulatory burden for visitors and eco-tourism operators (Queensland Government, 2012a, Queensland Government, 2012c). This has led to concern that the cardinal principle ${ }^{4}$ embodied in the Queensland Biodiversity Strategy and the Queensland Parks and Wildlife Service (QPWS) Master Plan is being eroded (Williams, 2012).

The paper proceeds with a brief discussion on the issue of rationing access to protected natural areas. This is followed by an introduction to the case study site and an outline of survey design. Model and welfare estimates are then presented, before conclusions are drawn.

\footnotetext{
${ }^{3}$ Henderson, R. Director, Tourism and Visitor Management, Parks Division, Queensland Parks and Wildlife Service. Personal communication. 3 June 2006.

${ }^{4}$ Introduced in 1959, the cardinal principle determines that national parks have the highest protection of all land classes. Under this principle, outdoor recreation that is nature-based and ecologically sustainable is encouraged provided it does not conflict with or degrade other values such as the conservation of nature.
} 


\section{Rationing Access to Protected Natural Areas}

The practice of rationing access to protected natural areas has been controversial since it first became widespread in the United States in the 1970s. The imposition of policies designed to reduce, or manage, demand for access to natural areas remains one of the most contentious issues in protected area management today (Freimund and Cole, 2001). The arguments put forward by those who oppose the imposition of rationing or demand management policies are extensive. Many argue that indirect, non-regulatory measures (e.g. education) should be attempted before regulatory measures and that these might succeed in alleviating the problem without unnecessarily impinging on the rights of visitors (Hall, 2001). Hendee et al. (1990) go further, concluding that although use-limits may be the only alternative in some cases, “...direct rationing of use should be a last resort after every other appropriate approach has been exhausted” (p.406).

One of the more compelling arguments against the use of rationing or demand management mechanisms is evidence of a non-linear relationship between use and impact, either on the environment or on recreational experience. In relation to the former, research has shown that most impacts occur at relatively low levels of use, with many impacts exceeding thresholds after very little use and further use having little additional impact (Cole and Fichtler, 1983, Cole, 1992). This suggests use-levels would have to be severely reduced to bring about noticeable improvements in the environment. Further arguments against rationing access are that: (1) use-limit policies, as commonly implemented, provide no incentive for individual visitors to reduce impacts (since merit is generally not a basis for allocating use) and; (2) use-limits in one area may simply lead to visitors moving elsewhere, displacing, rather than fixing the problem (McCool, 2001).

A key concern is the distributional consequences of rationing policies. Depending upon the rationing mechanism used, use-limits favour certain visitors over others. At a primary level, rationing favours those tolerant of regulation and in search of solitude, at the expense of those who favour freedom and spontaneity; of course the reverse is true if the decision is made not to impose rationing policies (Hall, 2001). 
In contrast, those who support the use of rationing or demand management mechanisms point to a body of literature indicating that, when faced with protected natural areas being used beyond capacity, visitors are generally supportive of use-limits. For example, in one of the earliest studies, Fazio and Gilbert (1974) find that 86 per cent of successful and, somewhat remarkably, 80 per cent of unsuccessful applicants for permits to visit Rocky Mountain National Park in Colorado were supportive of rationing; a result supported by a number of subsequent studies (cf. Cole et al., 1997, Cole, 2001, Bultena et al., 1981). There is, however, evidence to suggest that these findings might be culture-specific (cf. Williams, 2001) and no comparable research has been undertaken in an Australian context. Moreover, as noted by Shelby et al. (1989b, 1989a), in order to develop allocation systems that are acceptable to users, managers need information about their preferences for different allocation mechanisms. This area of inquiry remains under-researched outside of North America.

\section{A re-categorisation of 'rationing' mechanisms}

The leisure science literature typically identifies five mechanisms or management practises that can be used to allocate or ration scarce recreational resources: pricing; queuing; merit; advanced reservation; and lottery (cf. Shelby and Heberlein, 1986, Manning, 1999, Stankey and Baden, 1977). This list of mechanisms is neither exhaustive, nor entirely consistent with a supply-demand framework. Thus, this list is re-categorised and extended below.

To illustrate the logic behind this re-categorisation, assume there is a unique recreational site with a demand curve $\mathrm{D}_{0}$ and a pre-determined desired maximum level of visitation $\mathrm{Q}_{\mathrm{MAX}}$. This site is subject to a nominal entry fee $\mathrm{P}_{\mathrm{N}}$ and has a current level of visitation $\mathrm{Q}_{0}$. We therefore have a situation of excess demand (point A), depicted in Figure 1.

\section{[Insert Figure 1 here]}

Restricting our attention to demand management strategies only, there are three means of reducing the level of visitation to the maximum desired level. The first is to raise entry fees to $\mathrm{P}^{*}$, as depicted by point B in Figure 2. This is referred to as rationing by price. 


\section{[Insert Figure 2 here]}

A particular form of rationing by price, peak pricing, works by charging a higher entrance fee during times where demand for access to the recreational site is typically higher, for example weekends and public holidays. That is, there are two demand curves, one for off-peak periods and one for peak periods. In order to maintain visitation at $\mathrm{Q}_{\mathrm{MAX}}$, two prices are needed, with the peak-price exceeding the off-peak price. This is depicted by points A (off-peak) and B (peak) in Figure 3.

\section{[Insert Figure 3 here]}

The second means of reducing the level of visitation to the maximum desired level is to reduce demand for access to the site, as depicted by point B in Figure 4. There are at least two possible methods of achieving this; increasing the difficulty of accessing the site or lowering the site's relative profile (known as 'demarketing').

\section{[Insert Figure 4 here]}

The final means of reducing the level of visitation is to require visitors to obtain a permit to visit the site and then restrict the number of permits issued (i.e. impose a quota). In practise this is by far the most common means of rationing access to protected natural areas, however the problem then becomes one of allocating these permits among potential visitors. As depicted in Figure 5, there is a shortage of permits represented by the line CD. Potential allocation methods include queuing, advanced reservation, lottery and merit.

\section{[Insert Figure 5 here]}

In summary, there are at least four rationing (or demand management) mechanisms (price, physical constraints, demarketing and quotas) and, if imposing a quota is chosen, at least four potential allocation mechanisms (queuing, advanced reservation, lottery and merit). The distinction between rationing and allocation mechanisms is typically not made in the leisure science literature. 


\section{Lake McKenzie, Fraser Island}

Situated less than five kilometres off the Queensland coast, at the southern end of the Great Barrier Reef and some 250 kilometres north of Brisbane (see Figure 6), Fraser Island is the largest sand island in the world and one of Australia's iconic natural attractions. Inscribed under criteria (vii) and (ix) $)^{5}$ on the World Heritage List in 1992, the Island attracts in excess of 300,000 visitors per year (Fraser Island Defenders Organization, 2006). ${ }^{6}$ The annual recreational value of independent visitors to the Island has been estimated at $\$ 191$ million $^{7}$ (Fleming and Cook, 2008).

This level of visitation poses some significant threats to the Island's environment and the recreational experience of visitors. In regards to the former, visitors contribute to a range of environmental problems including erosion, litter disposal, human-wildlife interactions and contamination of the Island's freshwater resources (Hadwen and Arthington, 2003). The impact of the current level of visitation on the recreational experience is less well understood. In a survey of visitors to the Island in 2002, Tourism Queensland (2002) reports an overall mean visitor satisfaction score of 4.59 out of five, with 64 per cent of respondents reporting to be 'very satisfied' with the Island, and a further 30 per cent reporting to be 'satisfied'. However, it should be noted that while respondents were asked to report their level of satisfaction with 26 different aspects of their visit to Fraser Island, ranging from the price of petrol (the aspect with the lowest satisfaction rating) to the weather (the aspect with the highest rating), respondents were not asked to comment on the management of the Island, nor on the number, and behaviour, of other visitors.

\footnotetext{
${ }^{5}$ Criteria (vii) - to contain superlative natural phenomena or areas of exceptional natural beauty and aesthetic importance. Criteria (ix) - to be outstanding examples representing significant on-going ecological and biological processes in the evolution and development of terrestrial, fresh water, coastal and marine ecosystems and communities of plants and animals. UNITED NATIONS EDUCATIONAL SCIENTIFIC AND CULTURAL ORGANIZATION 2007. Fraser Island, Available: http://whc.unesco.org/en/list/630..

${ }^{6}$ More recent, unsubstantiated, estimates put the number of visitors closer to 500,000. ALEXANDER, N. 2009. Concerns heightening for Fraser Island's dingoes. Ecos, 151, 18-19.

${ }^{7}$ Unless otherwise stated, all figures are in AUD. As at 13 March 20141 AUD $=0.91$ USD.
} 
In contrast to this relatively positive assessment, in its first periodic report on the Island, the Fraser Island World Heritage Area Scientific Advisory Committee acknowledged that there is potential for changes to occur in the visitor experience as visitor numbers increase. According to the Committee, these changes could be attributed to overcrowding in high use areas and to increased interaction between visitors in more isolated parts of the Island. Moreover, the potential for recreation succession (the phenomenon whereby visitors seeking a wilderness experience are displaced by the 'mass tourist') and homogenisation of the visitor experience are specifically highlighted as threats to the diversity of opportunities offered by Fraser Island. The Committee went on to recommend that “...visitor management should be a priority action in order to minimise resource impacts and optimise the quality of visitor experiences and visitor safety.” (Queensland Environmental Protection Agency, 2002).

\section{[Insert Figure 6 here]}

Lake McKenzie is arguably the most marketed and renowned site on Fraser Island. The Lake has a long history of conflict between user groups ${ }^{8}$ and has been ranked the site most under pressure from tourism (Hadwen et al., 2003). If the Lake’s environment continues to degrade, particularly if nutrient levels rise, there is a risk of unsightly and damaging algae blooms. Moreover, current levels of visitation are a source of frustration for visitors, as existing infrastructure, including the car park, becomes congested.

An evaluation of desired site capacities on Fraser Island undertaken on behalf of the Island's managers (the QPWS) finds that Lake McKenzie has an average daily visitation rate of 350 people in off-peak periods, rising to an average of 1,200 people during peak times. This makes Lake McKenzie the second most visited site on the Island (EDAW, 2002). The report concludes by noting that current usage of the site exceeds its carrying capacity in terms of desired recreational experience within a World Heritage Area. Further, this level of visitation generates unacceptable levels of site-specific environmental impacts such as erosion in car parks, effluent treatment and general appearance, as well

\footnotetext{
${ }^{8}$ A full discussion of the history of conflict on Fraser Island is provided by: FLEMING, C. 2013. Rationing Access to Protected Natural Areas: An Economic Analysis based on a Study of Visitors to a World Heritage Site in Australia. Doctor of Philosophy University of Queensland.
} 
as perceived crowding and noise. Thus the report's authors recommend that the carrying capacity of Lake McKenzie, under current levels of infrastructure development, be reduced by approximately 25 per cent.

\section{Survey Design}

A choice modelling survey was employed in order to obtain information about independent visitors' preferences for alternative management regimes. A pilot survey was conducted at Rainbow Beach (one of the main access points to Fraser Island). One hundred surveys were distributed with pre-paid envelopes attached, of which 36 were returned; yielding some valuable insights in terms of questionnaire design. The main alteration to the questionnaire resulting from the pilot was a reduction in the number of questions from 30 to 26 . Specifically, the number of choice questions was reduced from six to four due to concerns about respondent fatigue when faced with a number of similar and repetitive questions.

The final questionnaire consists of six sections, 11 pages and 26 questions. ${ }^{9}$ On-site sampling was undertaken on two occasions during 2006, the first in April and the second in August. In April, 800 questionnaires were distributed over a period of seven days and in August, 560 questionnaires were distributed over a period of eight days. ${ }^{10}$ In both cases, questionnaires were distributed at a range of locations, predominantly in the lower third of the Island. Following the method of Wilson and Tisdell (2004), visitors were given questionnaires with pre-paid self-addressed envelopes attached. This provided respondents the opportunity to carefully consider replies in their own time. In addition, a copy of the survey was placed on-line. The web-based survey was constructed using Macromedia Dreamweaver $\mathrm{MX}^{\mathrm{TM}}$ for Windows. To ensure the validity of any comparison between the two survey administration modes, the web-based questionnaire was constructed to look as similar as possible to that distributed on-site. A link to the website was then placed on a number of Fraser Island tourism information websites with the simple invitation 'Visited Fraser Island recently? Click here to fill in a survey on the future management of the Island'. In total, across both survey modes, 576 usable

\footnotetext{
${ }^{9}$ A copy of the survey is available from the author on request.

${ }^{10}$ The difference in survey numbers reflects the fact that August is a much quieter time of year on the Island.
} 
responses were obtained, a response rate of 32 per cent. Full details of survey method and a comparison of the on-site and on-line survey can be found in Fleming and Bowden (2009).

The choice modelling technique relies on the idea that any good can be described in terms of its attributes and the levels these take. Clearly, therefore, determining the appropriate attributes to present to respondents to describe the good, or in this case policy scenario, under consideration is critical to the success of the choice modelling exercise. In determining which attributes to include, two perspectives are taken into account. First, the attributes need to be relevant to the policy making process, and in this application should therefore be consistent with policy instruments and outcomes considered plausible by the QPWS. Second, the attributes must have meaning to survey respondents (visitors to Fraser Island). Following consultation with the QPWS, both at head office and ranger level, discussion with other choice modelling practitioners and previous visitors to the Island, four attributes were chosen for inclusion within the choice model. These are: visitor management (or rationing mechanism); cost of vehicle access; quality of the environment; and the number of visitors encountered while at Lake McKenzie.

In regards to the visitor management attribute, three rationing mechanisms are proposed: a visitor cap; 4WD access restrictions; and peak pricing. The visitor cap is described to respondents as involving the placement of a limit on the number of Recreation Areas Management (RAM) vehicle access permits issued in any one calendar month (these permits are required by those taking a vehicle on to Fraser Island). 4WD access restrictions are described as involving closure of the current 4WD access road to Lake McKenzie, thus requiring those wishing to visit the Lake to walk for approximately 30 minutes from a newly designated parking spot. ${ }^{11}$ Peak pricing is described as involving the doubling

\footnotetext{
${ }^{11}$ Reducing the level of visitation to a nature-based recreation site by making access more difficult was first suggested by Tibor Scitovsky, who put it forward as a more equitable solution to over-visitation than charging an entrance fee; a position later supported by Garrett Hardin. See: SCITOVSKY, T. 1964. Equity. In: SCITOVSKY, T. (ed.) Papers on Welfare and Growth. California: Stanford University Press. HARDIN, G. 1969. The economics of wilderness. Natural History, 78, 20-27.
} 
of RAM vehicle access permit prices during the peak visitation months of January, April, September and December. In addition, a maintain existing practices (i.e. open access) option is included.

The cost of vehicle access attribute is described in terms of the existing RAM fee. The creation of a hypothetical Lake McKenzie site-specific entry charge was considered, but rejected, as discussion with the QPWS suggested that such a charge is highly unrealistic from a policy perspective. The use of an existing charge as the monetary attribute has the advantage of being familiar to respondents and should therefore be credible. To enhance acceptability, respondents are informed that, like existing revenue, all future revenue goes towards managing the Island and that all other costs remain unchanged.

The environmental quality attribute is described in terms of terrestrial and aquatic quality. Draft surveys contained two environmental attributes, one for the quality of the terrestrial environment and one for the quality of the aquatic environment. However, pre-testing of the survey and discussion with choice modelling practitioners raised concerns that these attributes were regarded by respondents as highly correlated or even causally-related. That is, respondents expected high (low) levels of terrestrial environmental quality to be always associated with high (low) levels of aquatic environmental quality and vice versa. This idea was therefore discarded and a combined terrestrial and aquatic environmental quality attribute created.

A visual approach is used to depict alternate levels of visitation to Lake McKenzie. This approach is preferred to relying on written descriptions such as 'high', 'medium' and 'low', largely because written descriptions are considered too open to interpretation; a 'medium' number of visitors to one person may well be a 'high' number of visitors to another. The use of the word 'crowding' is also avoided throughout the questionnaire, as it is considered to have too many negative connotations.

Adobe Photoshop 5.5 ${ }^{\mathrm{TM}}$ software was used to create three images with increasing levels of visitation labelled 'photo A', 'photo B' and 'photo C'. Care was taken to provide a balanced depiction of alternate levels of use, with the number of people increasing by 50 per cent at each increment (Figure 7). To mitigate the impact of respondents perceiving the number of visitors and environmental quality attributes to be causally-related, respondents were instructed to note that it is often the behaviour, 
rather than the number, of visitors that determines the environmental quality of a natural site. Pretesting of the survey suggests that respondents accepted that, unlike terrestrial and aquatic environmental quality, the number of visitors and environmental quality attributes could plausibly be uncorrelated. Final attributes and attribute-levels employed in this study are presented in Table 1.

The final combinations of attributes and attribute-levels to present to respondents was determined via the SAS OPTEX ${ }^{\mathrm{TM}}$ procedure (Kuhfeld, 1997). This procedure employs a Federov (1972) search algorithm to find the most efficient ${ }^{12}$ experimental design from the candidate set of all feasible attribute-level combinations. This procedure yielded 32 choice sets. As each respondent faced only four choice sets, SAS OPTEX ${ }^{\mathrm{TM}}$ was then used to construct eight blocks (i.e. eight sets of four choice sets).

A sample choice question is reproduced as Figure 8.

\section{[Insert Figure 7 here]}

\section{[Insert Table 1 here]}

\section{[Insert Figure 8 here]}

\section{Model Estimation}

The premise of choice modelling is that the respondent chooses ' $A$ ' if, and only if, option ' $A$ ' generates at least as much utility as any other option, with utility being assessed by trading off the attribute-levels of the available alternatives. The technique has two footholds in economic theory. The first of these is Lancaster's (1966) characteristics theory of value. This posits that any good can be described as a bundle of characteristics (or attributes) and the levels they take. The second foothold, and the one of particular relevance to model estimation, is random utility theory (Thurstone, 1927, McFadden, 1974). Random utility theory provides a conceptual framework where utility is divided into systematic (i.e. explainable) and random error components. The latter is used to capture unexplained variations in consumer choice behaviour. Assumptions about the distribution of the

\footnotetext{
${ }^{12}$ Designs are efficient in the sense that the precision of the parameter estimates is maximised.
} 
random error term underlie the statistical models generated from choice data, of which several specifications are available to the practitioner (Bateman et al., 2002, Vojacek and Pecakova, 2012).

In this study a mixed logit model is employed. This is the most flexible choice model and is increasingly popular among practitioners. All estimations are undertaken using the SAS MDC ${ }^{\mathrm{TM}}$ procedure (Kuhfeld, 2000) and models are estimated by simulated maximum likelihood using Halton quasi-random draws with 500 replications. All choice attributes are included as normally distributed random parameters to account for unobserved variation in respondents' preferences (Train, 2003).

A key objective of this study is to investigate differences in respondents' attitudes towards the management alternatives offered. As noted by Kragt and Bennett (2011), one way to reveal systematic preference heterogeneity is to introduce into the utility function an interaction term between socioeconomic/attitudinal variables and the choice attributes, and/or between socio-economic/attitudinal variables and an alternative specific constant (ASC). In this case an ASC is specified that takes a value of one if an alternative management option is chosen and zero otherwise. Model variables are defined in Table 2.

\section{[Insert Table 2 here]}

In the model with interactions, the ASC is interacted with socio-economic/attitudinal variables to determine possible sources of heterogeneity in respondents choosing the 'maintain existing practices' option as opposed to one of the 'ration access' options. Random choice parameters are also interacted with socio-economic/attitudinal variables to reveal any systematic heterogeneity towards the choice attributes. This process generated a very large number of variables. A number of models were initially estimated and compared across a range of selection criteria. In the interests of parsimony, interactions that did not improve the model were discarded.

\section{Results}

Results are presented in Table 3. Model 1 includes only choice attributes as explanatory variables, and Model 2 includes interactions. In both models, all estimated coefficients for random parameter means have the expected sign. The coefficients for 'VisitorCap' and '4WDAccess' are positive and 
significant. This, along with the coefficient for 'Maintain', implies that the coefficient for 'PeakPrice' is negative and that visitor caps and 4WD access restrictions are preferred to either maintaining the existing open access policy or the imposition of a peak price rationing mechanism. Similarly, the coefficients for 'EnvHigh' and 'EnvMed' are positive and significant. This, along with the coefficient for 'EnvLow', implies that the coefficient for 'EnvVLow' is negative and respondents are more likely to choose options with higher levels of environmental quality. The coefficients for 'VisitPhotoA' and 'VisitPhotoB' are positive and significant, implying that the coefficient for 'VisitPhotoC' is negative and that respondents prefer options with lower levels of crowding. As expected, the 'Cost' attribute is negative and significant, suggesting respondents are less likely to choose options with higher vehicle access fees. Importantly, the ASC parameter is positive and significant in both models. This indicates that respondents generally prefer a 'ration access' option over a continuation of the status quo.

Note that in Model 1 the standard deviation parameters for all attributes are significant at either the one per cent or five per cent level; suggesting significant unobserved taste heterogeneity. The model, however, does not provide information about the sources of this heterogeneity. Model 2, which includes interactions between socio-economic/attitudinal variables, the choice attributes and the ASC, is more revealing. Moreover, the inclusion of interaction terms improves the model's performance against all criteria of model fit.

Focusing first on the interacted random parameters, the negative and significant coefficients for the '4WDAccess' interaction variables suggest that when 4WD access restrictions are the chosen rationing mechanism, older visitors, males and those who own 4WDs are less likely to choose to introduce a rationing mechanism. In regards to older visitors, it is plausible that 4WD access restrictions are unattractive due to concerns about current or future mobility. For 4WD owners, the (often considerable) investment in these vehicles may make this group of visitors reluctant to see any restrictions imposed on their use. From a policy design perspective, this finding demonstrates the value of including interactions; the estimation of the attribute-only model suggests that both visitor caps and 4WD access restrictions are acceptable rationing mechanisms. The fact that there are no significant interaction variables for 'VisitorCap' suggests this may be a more broadly acceptable 
rationing mechanism; whereas imposing $4 \mathrm{WD}$ access restrictions is clearly unattractive to certain segments of visitors.

In regards to the non-random parameter interactions, the negative and significant coefficients for 'Age x ASC', 'Male x ASC', and '4WD x ASC' suggests older visitors, males and those who own 4WDs are generally less likely to opt to introduce some form of rationing, irrespective of the rationing mechanism under consideration. In contrast, the positive and significant coefficient for 'Education $\mathrm{x}$ ASC' and 'Visit x ASC' suggests that those with a tertiary degree and those who intend to visit Fraser Island again in the future are more likely to opt for some form of rationing mechanism.

\section{[Insert Table 3 here]}

\section{Welfare Estimates}

While it is tempting to look at the coefficients and draw inferences from those, care is needed in interpreting the coefficients associated with each attribute in logit models. While attribute signs and significance are relevant, it is important not to view coefficient estimates as direct representations of the contribution to overall utility of each of the attributes (Hensher et al., 2005).

The coefficients under a logit model, however, can be used to estimate the rate at which respondents are willing to trade off one attribute for another (i.e. the marginal rate of substitution). Where one of the attributes is monetary, the 'implicit price' of a change in the level of the non-monetary attributes can be obtained. In essence, the implicit price represents the amount of money that respondents are willing-to-pay in order to receive an improvement in the level of the non-monetary attribute.

Willingness-to-pay or implicit prices for changes in the level of environmental quality and changes in the level of use are presented in Table 4. Following the approach employed by Kragt and Bennett (2011), the willingness-to-pay measures are calculated using parametric bootstrapping techniques with 10,000 replications from the unconditional parameter estimates as specified by Krinsky and Robb (1986). The willingness-to-pay results are based on the random parameter estimates and account 
for unobserved heterogeneity in preferences by using the estimated standard deviations on the random parameters in the willingness-to-pay calculations. ${ }^{13}$

The first implication to be drawn from the willingness-to-pay estimates is that improvements in environmental quality are more highly valued by respondents than reductions in crowding; although both lead to relatively substantial welfare gains. The willingness-to-pay for an improvement in environmental quality from very low to high is $\$ 104.11$ (Model 1) and $\$ 119.89$ (Model 2) per respondent per trip; whereas the willingness-to-pay for a reduction in crowding from heavy (photo C) to light (photo A) is $\$ 79.06$ (Model 1) and $\$ 77.91$ (Model 2).

Another notable result is the extent to which diminishing returns sets in. As illustrated in Figure 9, the willingness-to-pay to move from a very low level of environmental quality to a low level is $\$ 54.24$ (Model 1) and \$70.59 (Model 2); to move from a low level to a medium level is \$38.92 (Model 1) and \$29.60 (Model 2); and from a medium level to a high level \$10.95 (Model 1) and \$19.70 (Model 2). Similarly, Figure 10 illustrates that for reductions in crowding the willingness-to-pay to move from heavy to moderate is $\$ 47.56$ (Model 1) and $\$ 42.37$ (Model 2); the willingness-to-pay to move from moderate to light is $\$ 31.50$ (Model 1) and \$35.54 (Model 2).

\section{[Insert Table 4 here]}

\section{[Insert Figure 9 here]}

\section{[Insert Figure 10 here]}

\section{Conclusion}

In regards to the primary questions of this paper, the finding that respondents are, in general, willing to trade off some degree of access rights for better environmental outcomes and reduced crowding is significant and contrary to the perceptions of many resource managers. This is particularly true when environmental outcomes are at stake; it is clear that improvements in environmental quality are more highly valued by respondents than reductions in crowding, although both lead to relatively substantial

\footnotetext{
${ }^{13}$ A full derivation of willingness-to-pay calculations is provided by: FLEMING, C. 2013. Rationing Access to Protected Natural Areas: An Economic Analysis based on a Study of Visitors to a World Heritage Site in Australia. Doctor of Philosophy University of Queensland.
} 
welfare gains. Moreover, diminishing implicit prices suggest most of the gains in welfare can be achieved with relatively minor improvements in the condition of the resource and the recreational experience.

The preferences of visitors for alternative management regimes, however, are by no means homogenous. While the positive and significant coefficients for the ASC parameter in both models suggests, on average, respondents prefer a ration access option over a continuation of the status quo, older visitors, males and those who own 4WD vehicles are more likely to opt for a continuation of current management practices. Those with a tertiary degree and respondents who state that they intend to visit Fraser Island again in the future, however, are less likely to choose this option. That is, they are more likely to opt for the introduction of some form of rationing mechanism.

In regards to alternative rationing mechanisms, the 'economists choice' (peak pricing) is not favoured by any group, even those on high incomes. ${ }^{14}$ It is clear that visitor caps and $4 \mathrm{WD}$ access restrictions are preferred to either maintaining the existing open access policy or the imposition of a peak pricing rationing mechanism; although older visitors, males and those who own 4WDs are less supportive of 4WD access restrictions than the rest of the population.

There are a number of caveats to these conclusions. First, the management of Fraser Island is an emotive issue. Among frequent visitors, the history of conflict between conservation and forestry and, more recently, conservation and recreation has taken its toll. QPWS' management of the Island is subject to considerable criticism and proposals for future management options may have been treated with a degree of scepticism or distrust. It is possible that the finding of a strong willingness to move from the status quo is, in part, a protest vote against the current management regime, rather than a careful consideration of the welfare implications of the alternative scenarios as they were described. In a related issue, caution is needed when generalising these findings to other sites. Fraser Island and Lake McKenzie are two of Queensland's most iconic and heavily visited protected natural areas. The willingness to forgo some degree of access found in this study may be site-specific and visitors may

\footnotetext{
${ }^{14}$ In unreported results, contrary to a priori expectations, no significant relationship could be found between 'Income' and 'PeakPrice'.
} 
not be so willing to trade off access rights to other recreational sites, particularly those they perceive to be less unique. Nonetheless, these findings raise serious questions about the level of community support for the Queensland State Government's aim of increasing access to protected natural areas; such an aim would seem to be directly counter to the preferences expressed by the visitors surveyed during this study.

There are a number of avenues for further research. Replicating this study at other, less iconic or heavily visited, sites is one. Another is to consider the mechanics of particular rationing mechanisms in more detail. More fundamentally, a worthwhile exercise could be to include alternative recreation management strategies among the potential options. The focus of this study was entirely on demand management. Managing supply, managing the resource and managing impact are all alternative strategies found in the leisure science literature. Information about visitors' preferences for these alternatives would be useful. 


\section{References}

ALEXANDER, N. 2009. Concerns heightening for Fraser Island's dingoes. Ecos, 151, 18-19.

BATEMAN, I., CARSON, R., DAY, B., HANEMANN, W., HANLEY, N., HETT, T., JONES-LEE, M., LOOMES, G., MOURATO, S., OZDEMIROGLU, E., PEARCE, D., SUGDEN, R. \& SWANSON, J. 2002. Economic Valuation with Stated Preference Techniques: A Manual, Cheltenham, Edward Elgar.

BULTENA, G., ALBRECHT, D. \& WOMBLE, P. 1981. Feedom versus control: A study of backpackers' preferences for wilderness management. Leisure Sciences, 4, 297-310.

COLE, D. 1992. Modeling wilderness campsites: Factors that influence amount of impact. Environmental Management, 16, 255-264.

COLE, D. 2001. Day users in wilderness: How different are they?, United States Department of Agriculture, Forest Service, Research Paper RMRS-RP-31, Rocky Mountain Research Station, Ogden.

COLE, D. \& FICHTLER, R. 1983. Campsite impact on three western wilderness areas. Environmental Management, 7, 275-288.

COLE, D., WATSON, A., TROY, E. \& SPILDIE, D. 1997. High-use destinations in wilderness: Social and biophysical impacts, visitor responses, and management options, United States Department of Agriculture, Forest Service, Research Paper INT-RP-496 Intermountain Research Station, Ogden.

EDAW 2002. Fraser Island desired site capacities study: Final Report, Brisbane, Queensland Environmental Protection Agency.

FAZIO, J. \& GILBERT, D. 1974. Mandatory wilderness permits: Some indications of success. Journal of Forestry, 72, 753-756. 
FEDEROV, V. 1972. Theory of Optimal Experiments, New York, Academic Press.

FLEMING, C. 2013. Rationing Access to Protected Natural Areas: An Economic Analysis based on a Study of Visitors to a World Heritage Site in Australia. Doctor of Philosophy University of Queensland.

FLEMING, C. \& BOWDEN, M. 2009. Web-based surveys as an alternative to traditional mail methods. Journal of Environmental Management, 90, 284-292.

FLEMING, C. \& COOK, A. 2008. The recreational value of Lake McKenzie, Fraser Island: An application of the travel cost method. Tourism Management, 29, 1197-1205.

FRASER ISLAND DEFENDERS ORGANIZATION 2006. Visitor numbers, Available: http://www.fido.org.au/moonbi/moonbi113/moonbi113.pdf.

FREIMUND, W. \& COLE, D. 2001. Use density, visitor experience, and limiting recreational use in wilderness: Progress to date and research needs. In: FREIMUND, W. \& COLE, D. (eds.) Visitor Use Density and Wilderness Experience: Proceedings June 1-3, 2000. Missoula: Rocky Mountain Research Station.

HADWEN, W. \& ARTHINGTON, A. 2003. The significance and management implications of perched dune lakes as swimming and recreation sites on Fraser Island, Australia. Journal of Tourism Studies, 14, 35-44.

HADWEN, W., ARTHINGTON, A. \& MOSISCH, T. 2003. The impact of tourism on dune lakes on Fraser Island, Australia. Lakes and Reservoirs: Research and Management, $8,15-26$.

HALL, T. 2001. Use limits in wilderness: Assumptions and gaps in knowledge. In: FREIMUND, W. \& COLE, D. (eds.) Visitor Use Density and Wilderness Experience: Proceedings June 1-3 2000. Missoula: Rocky Mountain Research Station. 
HARDIN, G. 1968. The tragedy of the commons. Science, 162, 1243-1248.

HARDIN, G. 1969. The economics of wilderness. Natural History, 78, 20-27.

HENDEE, J., STANKEY, G. \& LUCAS, R. 1990. Wilderness Management, Golden, Colorado, North American Press.

HENSHER, D., ROSE, J. \& GREENE, W. 2005. Applied Choice Analysis: A Primer, Cambridge, Cambridge University Press.

KRAGT, M. \& BENNETT, J. 2011. Using choice experiments to value catchment and estuary health in Tasmania with individual preference heterogeneity. Australian Journal of Agricultural and Resource Economics, 55, 159-179.

KRINSKY, I. \& ROBB, L. 1986. On approximating the statistical properties of elasticities. Review of Economics and Statistics, 66, 715-719.

KUHFELD, W. 1997. Efficient experimental designs using computerized searches, Sawtooth Software Research Paper Series, Sequim.

KUHFELD, W. 2000. Multinomial logit, discrete choice modeling. Research Paper No. TS621, SAS Institute Inc,. Cary.

LANCASTER, K. 1966. Change and innovation in the technology of consumption. American Economic Review, 56, 14-23.

MANNING, R. 1999. Studies in Outdoor Recreation: Search and Research for Satisfaction, Corvallis, Oregon State University Press.

MCCOOL, S. 2001. Limiting recreational use in wilderness: Research issues and management challenges in appraising their effectiveness. In: FREIMUND, W. \& COLE, D. (eds.) Visitor Use Density and Wilderness Experience: Proceedings June 1-3 2000. Missoula: Rocky Mountain Research Station. 
MCFADDEN, D. 1974. Conditional logit analysis of qualitative choice behavior. In: ZAREMBKA, P. (ed.) Frontiers in Econometrics. New York: Academic Press.

QUEENSLAND ENVIRONMENTAL PROTECTION AGENCY 2002. Australian national periodic report: Section II, report on the state of conservation of Fraser Island, Brisbane.

QUEENSLAND GOVERNMENT. 2012a. Amendments to increase eco-tourism and cut redtape $\quad$ [Online]. Available: Available: http://statements.qld.gov.au/Statement/2012/11/13/amendments-to-increaseecotourism-and-cut-redtape.

QUEENSLAND GOVERNMENT. 2012b. Interest groups have their say in Nature Conservation Act review [Online]. Available: Available: http://statements.qld.gov.au/Statement/2012/11/29/interest-groups-have-their-say-innature-conservation-act-review.

QUEENSLAND GOVERNMENT. 2012c. Vehicle access returns at two Moreton Island beaches [Online]. Available: Available: http://statements.qld.gov.au/Statement/2012/5/2/vehicle-access-returns-at-twomoreton-island-beaches.

SCITOVSKY, T. 1964. Equity. In: SCITOVSKY, T. (ed.) Papers on Welfare and Growth. California: Stanford University Press.

SHELBY, B. \& HEBERLEIN, T. 1986. Carrying Capacity in Recreation Settings, Corvallis, Oregon State University Press.

SHELBY, B., WHITTAKER, D. \& DANLEY, M. 1989a. Allocation currencies and perceived ability to obtain permits. Leisure Sciences, 11, 137-144. 
SHELBY, B., WHITTAKER, D. \& DANLEY, M. 1989b. Idealism versus pragmatism in user evaluations of allocation systems. Leisure Sciences, 11, 61-70.

STANKEY, G. \& BADEN, J. 1977. Rationing wilderness use: Methods, problems, and guidelines. United States Department of Agriculture Forest Research Service Research Paper INT-192. Ogden.

THURSTONE, L. 1927. A law of comparative judgment. Psychological Review, 34, 273286.

TOURISM QUEENSLAND 2002. Fraser Island visitor survey, Report prepared by the Tourism Queensland research department, Brisbane.

TRAIN, K. 2003. Discrete Choice Methods with Simulation, Cambridge, Cambridge University Press.

UNITED NATIONS EDUCATIONAL SCIENTIFIC AND CULTURAL ORGANIZATION 2007. Fraser Island, Available: http://whc.unesco.org/en/list/630.

VOJACEK, O. \& PECAKOVA, I. 2012. Comparison of discrete choice models for economic environmental research. Prague Economic Papers, 15, 35-53.

WILLIAMS, B. 2012. National parks to lose protection under legislative changes [Online]. Brisbane. Available: Available: http://www.couriermail.com.au/news/queensland/national-parks-to-lose-protectionunder-legislative-changes/story-e6freoof-1226537907740.

WILLIAMS, D. 2001. Sustainability and public access to nature: Contesting the right to roam. Journal of Sustainable Tourism, 9, 361-371. 
WILSON, C. \& TISDELL, C. 2004. Attitudes to entry fees to National Parks: Results and policy implications from a Queensland case study. Economic Analysis and Policy, 34, 79-102. 
TABLE 1 Final Attributes and Attribute-levels

\begin{tabular}{ll}
\hline Attributes & Attribute-levels ${ }^{1}$ \\
\hline Visitor management & Visitor cap, 4WD access restrictions, peak pricing, maintain existing \\
& practises \\
Cost of vehicle access & $\$ 20.00, \mathbf{\$ 4 0 . 0 0}, \$ 70.00, \$ 125.00^{2}$ \\
Quality of the environment & High, medium, low, very low \\
Number of visitors & Photo A, photo B, photo C \\
\hline
\end{tabular}

${ }^{1}$ Status quo or future base attribute-levels in bold.

${ }^{2}$ An upper bound of \$125 was selected following consultation with the QPWS and pre-testing of the survey. 
TABLE 2 Definition of Variables

Variable $^{1} \quad$ Definitions

Alternative specific constants

ASC Alternative specific constant, takes the value of 1 for an alternative management regime, or else 0 .

Attributes

Maintain Maintain existing practices (open-access).

VisitorCap Impose a visitor cap.

4WDAccess Impose 4WD access restrictions.

Cost Cost of vehicle access.

EnvHigh High quality of the environment.

EnvMed Medium quality of the environment.

EnvLow Low quality of the environment.

VisitPhotoA Visitation level associated with photo A.

VisitPhotoB Visitation level associated with photo B.

Socio-economic and attitudinal variables

Age $\quad$ Age of respondent, mid-point of selected range.

Male Dummy variable $=1$ if respondent is male

Income Income of respondent, mid-point of selected band.

Educ Dummy variable $=1$ if respondent has a tertiary qualification.

4WD Dummy variable $=1$ if respondent travelled in own 4WD.

Aust Dummy variable $=1$ if respondent an Australian resident.

Visit Dummy variable $=1$ if respondent intends to visit Fraser Island again in the 
future.

1 Excluded (base case) attribute-levels: Visitation level associated with Photo C (VisitPhotoC); very low quality of the environment (EnvVLow); and peak pricing (PeakPrice). 
TABLE 3 Estimation Results

\begin{tabular}{|c|c|c|c|c|}
\hline \multirow[t]{3}{*}{ Variable } & \multicolumn{2}{|l|}{ Model 1} & \multicolumn{2}{|l|}{ Model 2} \\
\hline & \multicolumn{2}{|c|}{ Attribute-only model ${ }^{1,2,3}$} & \multicolumn{2}{|c|}{ Model with interactions ${ }^{4,5,6}$} \\
\hline & Coefficient & s.e. & Coefficient & s.e. \\
\hline \multicolumn{5}{|c|}{ Random parameter means } \\
\hline Maintain & $-0.125 * * *$ & 0.055 & $-0.203 * * *$ & 0.054 \\
\hline VisitorCap & $0.264 * *$ & 0.081 & $0.293 * * *$ & 0.079 \\
\hline 4WDAccess & $0.165^{* * *}$ & 0.105 & $0.177 * * *$ & 0.102 \\
\hline Cost & $-0.008 * * *$ & 0.071 & $-0.01 * * *$ & 0.069 \\
\hline EnvHigh & $0.339 * * *$ & 0.200 & $0.477 * * *$ & 0.195 \\
\hline EnvMed & $0.249 * *$ & 0.052 & $0.278 * * *$ & 0.051 \\
\hline EnvLow & $-0.071^{* * *}$ & 0.050 & $-0.021^{* * *}$ & 0.049 \\
\hline VisitPhotoA & $0.303^{* *}$ & 0.175 & $0.382 * * *$ & 0.171 \\
\hline VisitPhotoB & $0.044^{* *}$ & 0.170 & $0.023 * * *$ & 0.166 \\
\hline \multicolumn{5}{|c|}{ Random parameter standard deviations } \\
\hline Maintain & $-0.029 * * *$ & 0.055 & $-0.031 * * *$ & 0.064 \\
\hline VisitorCap & $0.433 * *$ & 0.082 & $0.245^{* *}$ & 0.094 \\
\hline 4WDAccess & $0.739 * * *$ & 0.106 & $0.246^{* * *}$ & 0.122 \\
\hline Cost & $-0.009 * * *$ & 0.072 & $-0.009 * * *$ & 0.083 \\
\hline EnvHigh & $0.498 * *$ & 0.202 & $0.512 * * *$ & 0.233 \\
\hline EnvMed & $0.347 * * *$ & 0.053 & $0.333 * * *$ & 0.061 \\
\hline EnvLow & $-0.146 * * *$ & 0.050 & $-0.097 * *$ & 0.058 \\
\hline VisitPhotoA & $0.789 * * *$ & 0.177 & $0.599 * * *$ & 0.204 \\
\hline
\end{tabular}


VisitPhotoB

$0.009 * * *$

0.172

$0.002 * * *$

0.198

Heterogeneity in mean of random parameters

4WDAccess x Age

$-0.127 * * *$

4WDAccess x Male

$-0.557^{* * *}$

4WDAccess x 4WD

$-0.443^{* * *}$

Non-random parameters

ASC

$1.898^{* * *}$

0.298

$1.961^{* * *}$

0.310

Age x ASC

$-0.228 * * *$

Male x ASC

$-0.093 * * *$

Education x ASC

$0.503 * * *$

4WD x ASC

$-0.692^{* * *}$

Visit x ASC

$0.145^{* * *}$

Model statistics

Log likelihood

$-2,138$

$-1,986$

Pseudo rho-square

0.27

0.31

Normalised AIC ${ }^{1}$

1.41

1.38

Normalised BIC ${ }^{2}$

1.43

1.40

$\mathrm{N}$ (choice sets)

2,304

2,304

*** Significant at $1 \%$ level, ** Significant at $5 \%$ level, *Significant at $10 \%$ level;

1 The coefficients for Maintain, VisitorCap and 4WDAccess together imply a coefficient for PeakPrice of $-(-0.125+0.264+0.165)=-$ 0.304

2 The coefficients for EnvHigh, EnvMed and EnvLow together imply a coefficient for EnvVLow of $-(0.339+0.249+-0.071)=-0.517$.

3 The coefficients for VisitPhotoA and VisitPhotoB together imply a coefficient for VistiPhotoC of $-(0.303+0.044)=-0.347$.

4 The coefficients for Maintain, VisitorCap and 4WDAccess together imply a coefficient for PeakPrice of $-(-0.203+0.293+0.177)=-$ 0.267 . 
5 The coefficients for EnvHigh, EnvMed and EnvLow together imply a coefficient for EnvVLow of $-(0.477+0.278+-0.021)=-0.734$.

6 The coefficients for VisitPhotoA and VisitPhotoB together imply a coefficient for VistiPhotoC of $-(0.382+0.023)=-0.405$.

7. AIC normalised to the number of observations.

8. Bayesian Information Criterion (BIC) normalised to the number of observations. 
TABLE 4 Median Willingness-to-pay Estimates

\begin{tabular}{lcc}
\hline Shift in Attribute Level & $\begin{array}{c}\text { Model } 1 \\
\text { Attribute-only Model }\end{array}$ & $\begin{array}{c}\text { Model } 2 \\
\text { Model with Interactions }\end{array}$ \\
\hline EnvVLow to EnvLow & $\$ 54.24$ & $\$ 70.59$ \\
EnvLow to EnvMed & $\$ 38.92$ & $\$ 29.60$ \\
EnvMed to EnvHigh & $\$ 10.95$ & $\$ 19.70$ \\
EnvVLow to EnvHigh & $\$ 104.11$ & $\$ 119.89$ \\
VisitPhotoC to VisitPhotoB & $\$ 47.56$ & $\$ 42.37$ \\
VisitPhotoB to VisitPhotoA & $\$ 31.50$ & $\$ 35.54$ \\
VisitPhotoC to VisitPhotoA & $\$ 79.06$ & $\$ 77.91$ \\
\hline
\end{tabular}


FIGURE 1 Excess Demand

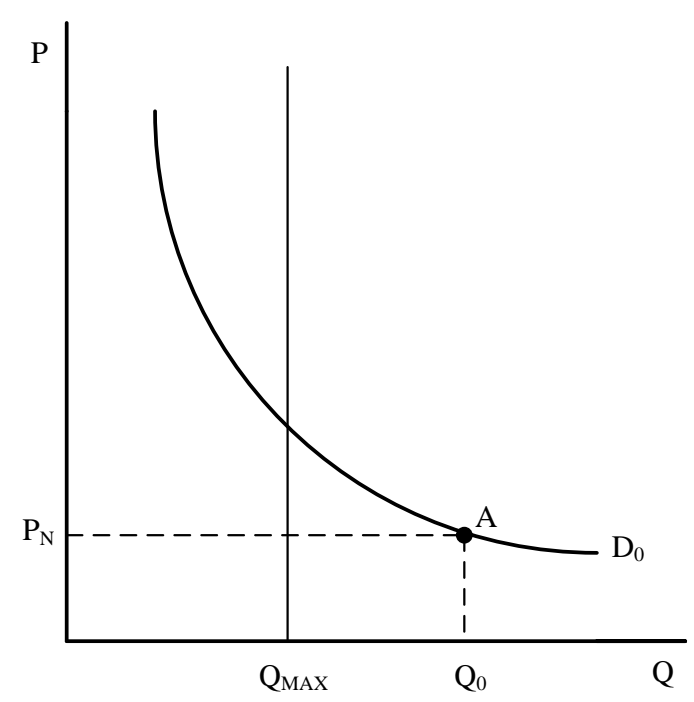


FIGURE 2 Rationing by Price

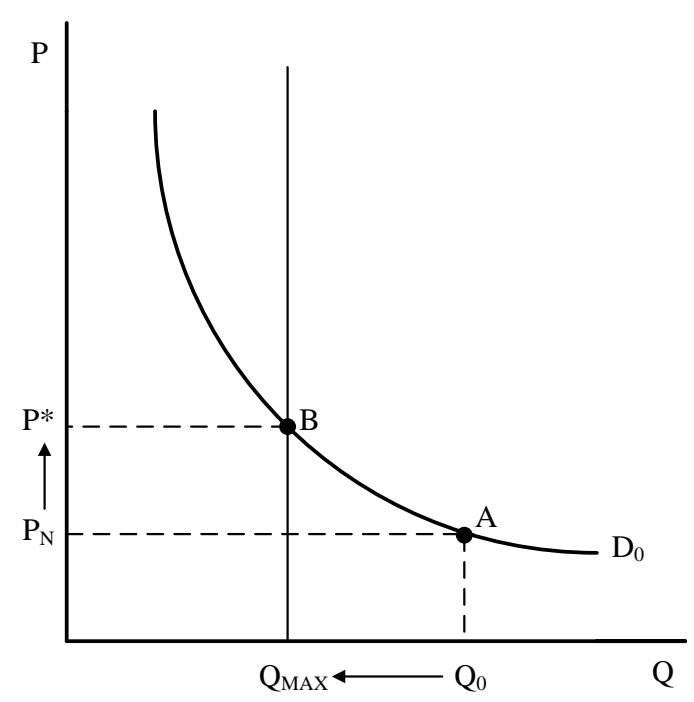




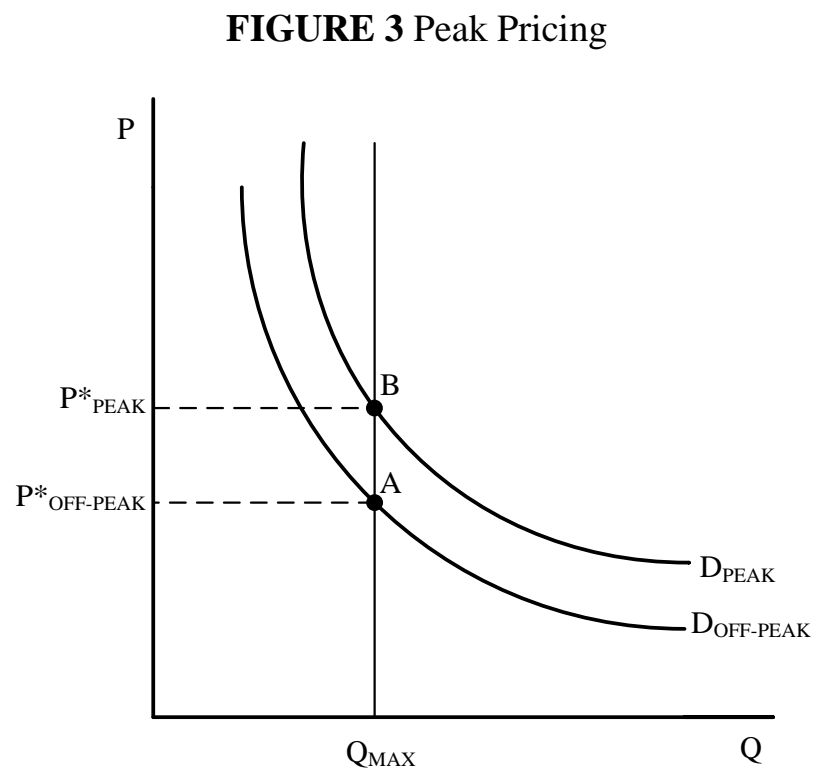


FIGURE 4 Reducing Demand

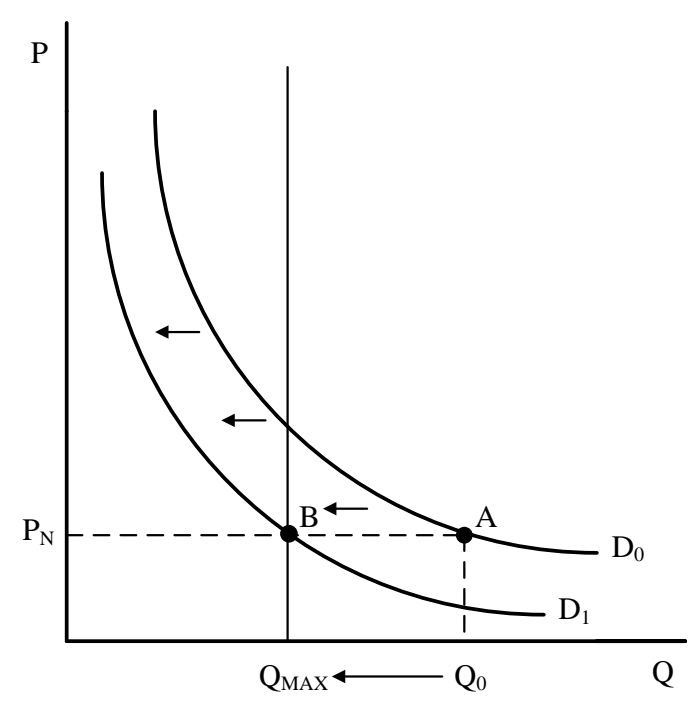


FIGURE 5 Use of Quotas

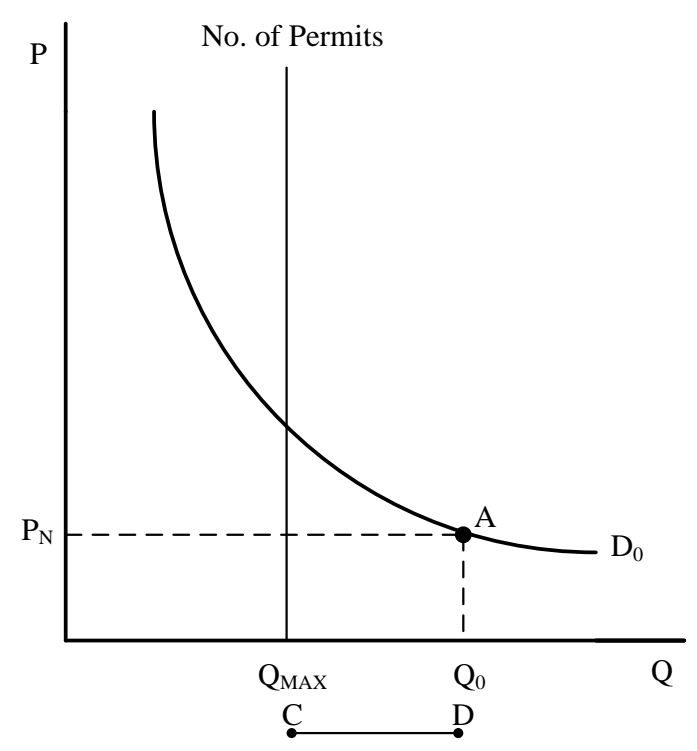


FIGURE 6 Fraser Island and Lake McKenzie

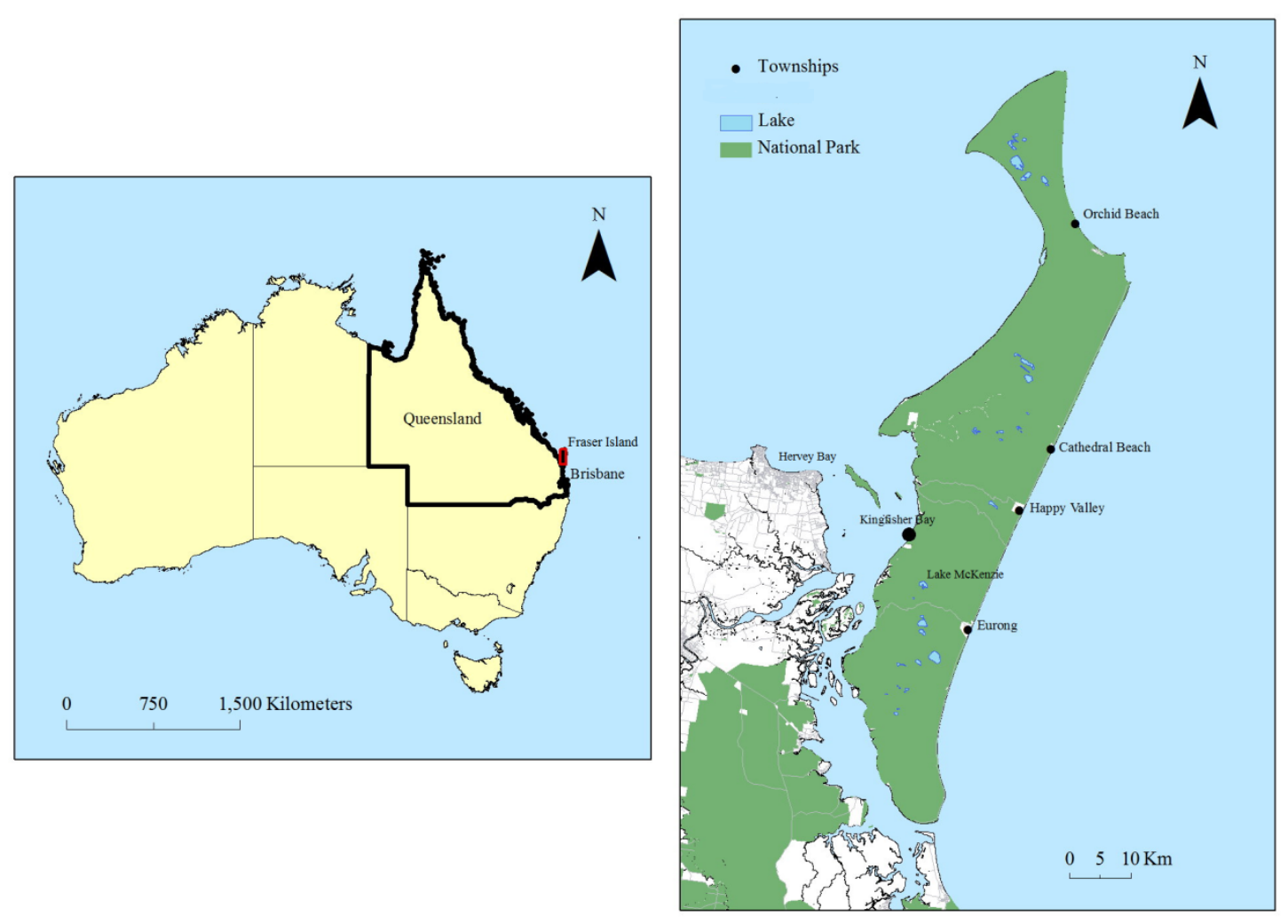


FIGURE 7 Photos Depicting Alternate Levels of Visitation
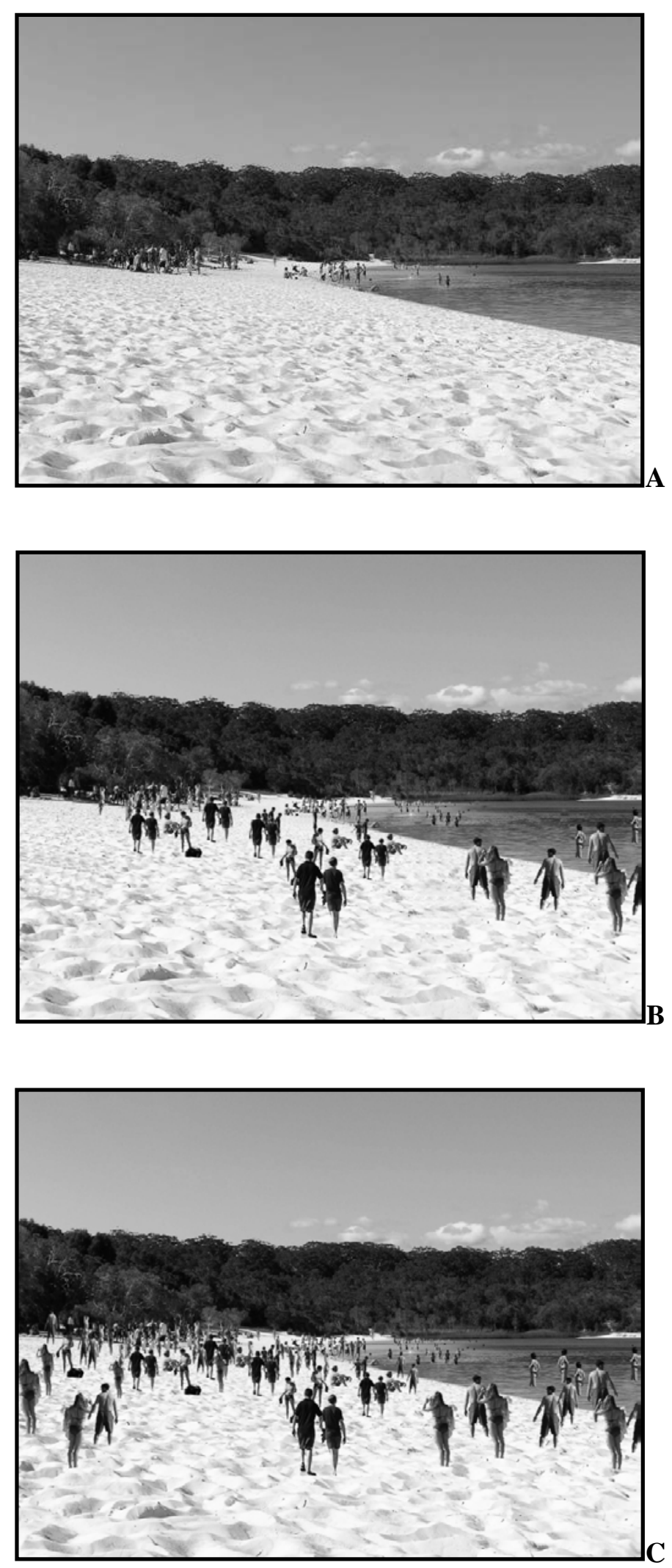
FIGURE 8 An Example of a Choice Question used in this Study

Suppose the following options were the only options available for Lake McKenzie in 2012. Please indicate which option you prefer by crossing one of the boxes in the shaded column below.

\begin{tabular}{|c|c|c|c|c|}
\hline $\begin{array}{c}\text { VISITOR } \\
\text { MANAGEMENT }\end{array}$ & $\begin{array}{c}\text { COST OF } \\
\text { VEHICLE } \\
\text { ACCESS }\end{array}$ & $\begin{array}{c}\text { QUALITY OF } \\
\text { THE } \\
\text { ENVIRONMENT }\end{array}$ & $\begin{array}{c}\text { NUMBER OF } \\
\text { VISITORS }\end{array}$ & $\begin{array}{c}\text { I WOULD } \\
\text { CHOOSE } \\
\text { OPTION }\end{array}$ \\
\hline Visitor Cap & $\$ 125$ & Medium & Photo A & $\square 1$ \\
\hline $\begin{array}{c}\text { 4WD Access } \\
\text { Restrictions }\end{array}$ & $\$ 20$ & High & Photo B & $\square 2$ \\
\hline $\begin{array}{c}\text { Maintain Existing } \\
\text { Practices }\end{array}$ & $\$ 40$ & Very Low & Photo C & $\square 3$ \\
\hline
\end{tabular}


FIGURE 9 Diminishing Returns to Environmental Improvement

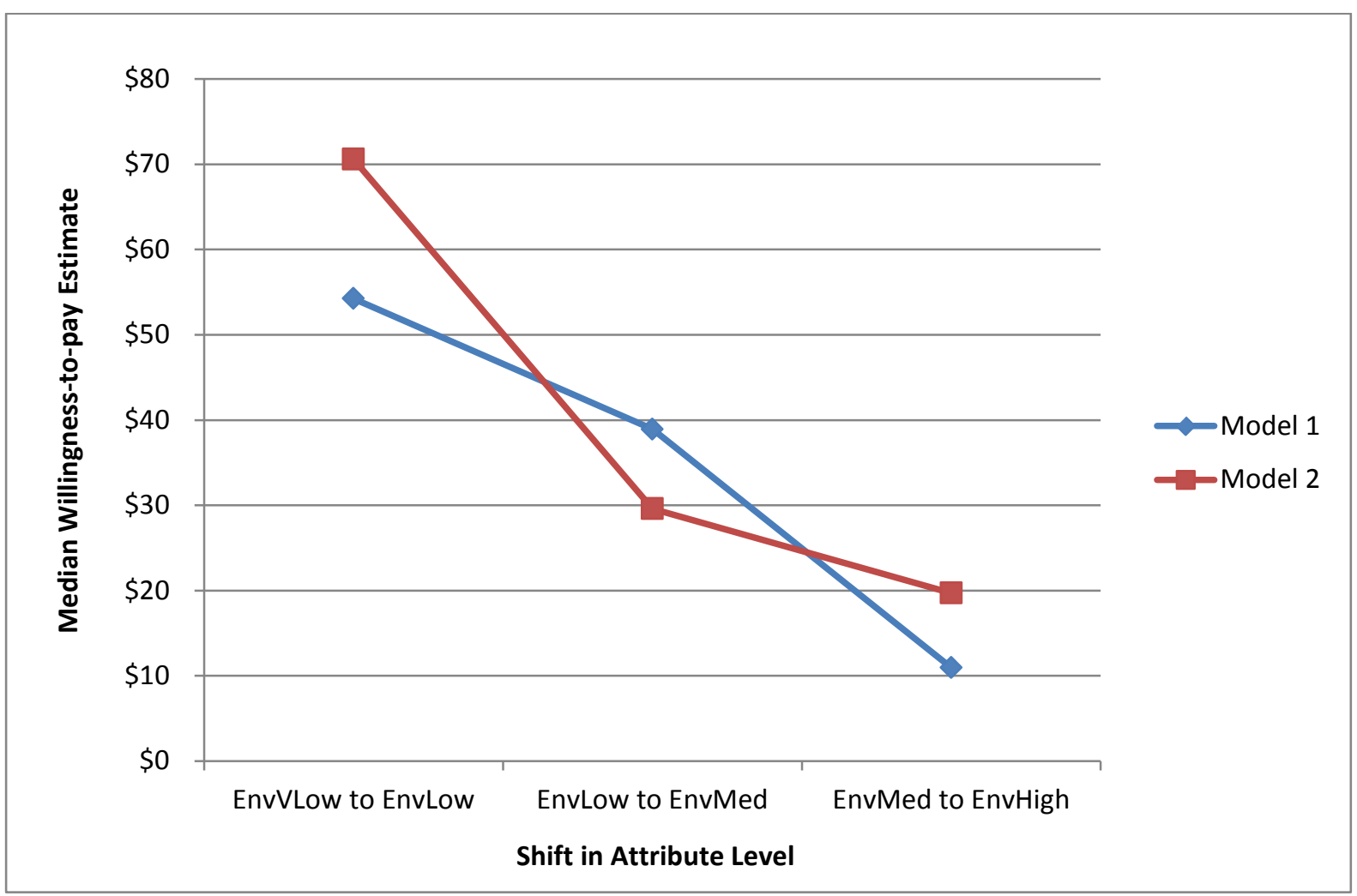


FIGURE 10 Diminishing Returns to Reduced Crowding

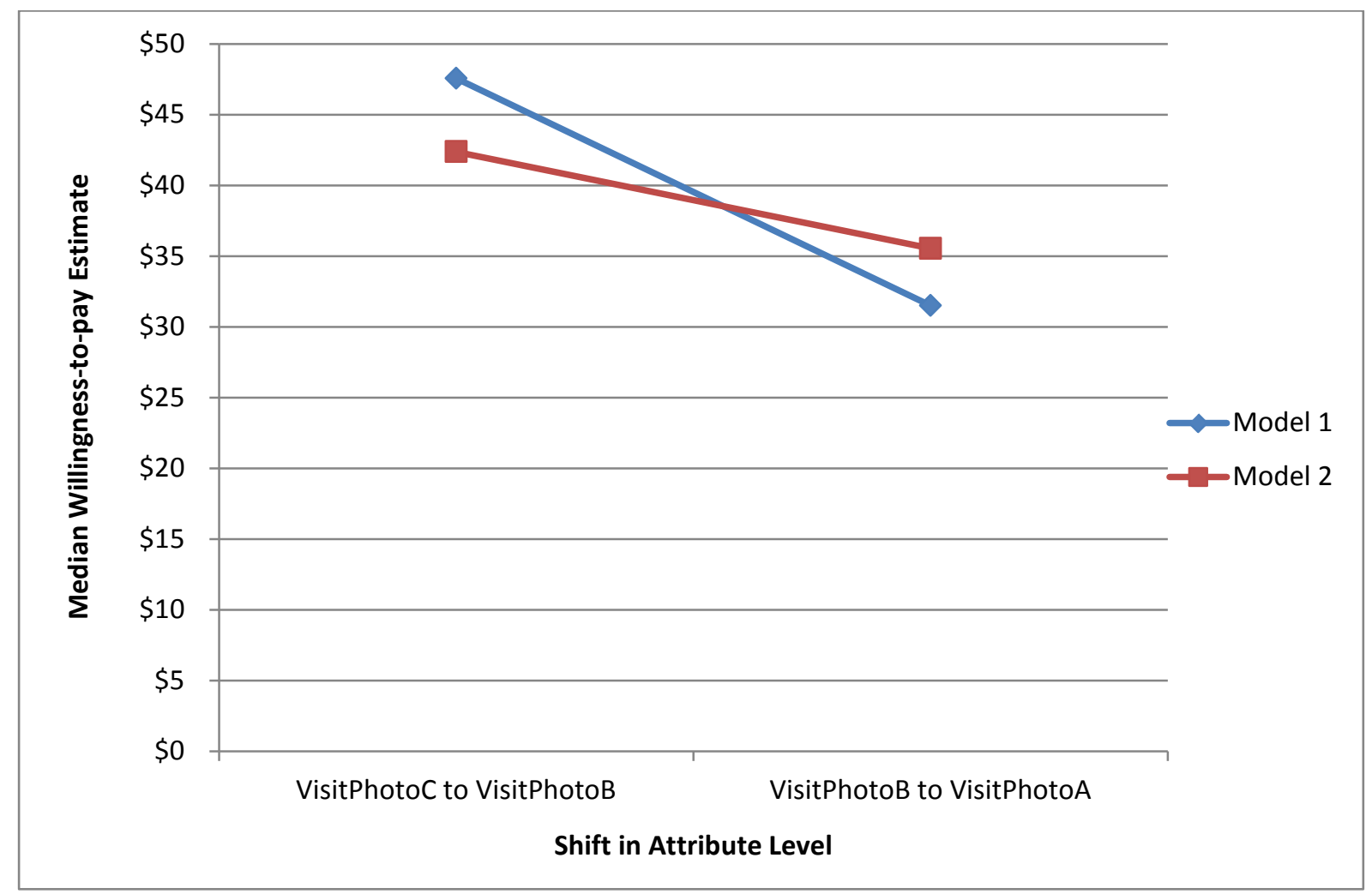

